\title{
ANALISIS NILAI TAMBAH PENGOLAHAN KOPI ARABIKA DI KELOMPOK TANI SEJAHTERA KABUPATEN SITUBONDO
}

\author{
Puryantoro ${ }^{1^{*}}$ \\ ${ }^{1}$ Program Studi Agribisnis, Fakultas Pertanian, Universitas Abdurachman Saleh \\ ${ }^{*}$ Corresponding author : puryantoro@unars.ac.id \\ To cite this article: \\ Puryantoro, P. (2021). Analisis Nilai Tambah Pengolahan Kopi Arabika Di Kelompok Tani Sejahtera Kabupaten \\ Situbondo. Jurnal IImiah Membangun Desa dan Pertanian, 6(1), 1 - 6. \\ doi:http://dx.doi.org/10.37149/jimdp.v6i1.16139
}

Received: January 22, 2021; Accepted: February 14, 2021; Published: February 21, 2021

\begin{abstract}
Coffee is one of the mainstay commodities in Situbondo Regency. Kayumas Village, Arjasa District is the best coffee producer that has ever received a national award. The Arabica coffee agroindustry carried out by farmer groups provides promising added value to the business world. This study aims to analyze the added value in the agro-industry of fullwash coffee and natural arabica in the Prosperous Farmer Group in Kayumas Village, Arjasa District, Situbondo Regency. Data collected in March 2020 through primary and secondary data were analyzed using the Hayami method. The results showed that the added value of processing Arabica coffee into full-wash and natural Arabica brewed coffee gave the same added value, namely Rp. 50,600 or $40.48 \%$ with different benefits. Fullawash got a profit of Rp. 47,600 / kg and naturally get a profit of Rp. 46,850 / kg.
\end{abstract}

Keywords: additional value; arabica; coffee

\section{PENDAHULUAN}

Salah satu produk pertanian di sektor perkebunan yaitu kopi mempunyai nilai strategis karena mampu memenuhi pasar domestik bahkan sebagai penghasil devisa karena menjadi salah satu produk impor (Hariyati, 2014). Kopi arabika paling banyak dihasilkan sekitar $70 \%$ dari jumlah produksi dan sisanya adalah 30\% untuk kopi robusta (Fauziah \& Ihwana, 2015). Di dunia, Indonesia ada pada posisi keempat (Harlina Dewi, Nusril, Helmiyetti, Rosalina, \& Sarumpaet, 2013)

Daerah yang cukup potensial untuk perkebunan kopi arabika adalah Kabupaten Situbondo dan telah mampu menembus pasar internasional. Menurut data Sensus Pertanian BPS Situbondo rumah tangga yang mengusahakan kopi mencapai 3,64 ribu rumah tangga. Kecamatan Sumbermalang, kecamatan Banyuglugur, dan kecamatan Arjasa menjadi lokasi rumah tangga usahatani kopi di Situbondo yang masing-masing sejumlah 2,01 ribu, 0,44 ribu, dan 0,95 ribu. Jumlah pohon kopi yang sudah berproduksi sebanyak 1.971,31 ribu pohon. Kecamatan Arjasa Desa Kayumas menjadi wilayah tertinggi yang mempunyai jumlah pohon kopi, yaitu sebanyak $1.867,35$ ribu pohon. (BPS Kabupaten Situbondo, 2020)

Kopi rakyat memberikan sumbangan yang cukup besar pada kesejahteraann petani. Harga kopi yang diterima produsen akan stabil melalui diversifikasi produk. Sehingga kelompok tani yang ada di Desa Kayumas Kecamatan Arjasa ini melakukan pengolahan kopi biji menjadi bubuk dalam kemasan dan rasa yang menarik konsumen. Full wash dan natural merupakan produk dari diversifikasi kopi arabika kayumas. Dalam penerapan agroindustri ini diperlukan kajian nilai tambah kopi arabika. Salah satunya adalah Kelompok Tani Sejahtera yang menjadi pelaku agroindustri kopi arabika fullwash dan natural.

Penelitian terdahulu pada umumnya telah menganalisa nilai tambah pada produk seperti penelitian Ramawati, Soedarto, Nurhadi, et al., (2019) yang menganalisa nilai tambah kopi robusta pada setiap tingkatan agroindustri mulai dari tingkatan pembersihan, pembersihan dan grading, kopi ose hingga ke tingkatan kopi bubuk. Yoga Priantara, Mulyani, \& Satriawan (2017a) dan (Dewi, Budiasa, \& Dewi, 2015) juga telah menganalisa nilai tambah kopi arabika jenis kopi Hs, kopi Ose dan kopi bubuk di Kabupaten Bangli. Sementara itu Subaeni, Badrudin, \& Reswita (2017) menganalisa 
nilai tambah kopi bubuk dan kopi durian pada kopi sahabat di Kota Lubuk Linggau. Semetara itu Murbaningtyas, Sukiyono, \& Badrudin (2020) juga telah melakukan penelitian dengan menganilsa nilai tambah pada pengolahan kopi menjadi kopi bubuk premium, sintaro, dan APA yang dilakukan oleh Kelompok Perkasa Tani. Penelitian yang menganalisa kopi arabika menjadi bubuk dengan jenis fullwash dan natural masih terbatas khususnya pada konteks nilai tambahnya. Dengan demikian, tujuan penelitian ini adalah menganlisa nilai tambah pengolahan kopi arabika menjadi bubuk kopi fullwash dan natural.

\section{MATERI DAN METODE}

Objek penelitian adalah anggota Kelompok Tani Sejahtera yang berlokasi di Desa Kayumas Kecamatan Arjasa Kabupaten Situbondo pada bulan Maret tahun 2020. Penentuan lokasi dengan teknik purposive karena kelompok ini merupakan penghasil kopi arabika di Situbondo.

Pengumpulan data primer melalui wawancara dengan key informan ketua kelompok tani Sejahtera. Sementara untuk data sekunder diperoleh melalui literature dan sumber lain sesuai permasalahan dan analisis penelitian. Data yang dikumpulan kemudian dianalisa dengan metode analitis. Data yang dikumpulkan dianalisa menggunakan perhitungan nilai tambah agroindustri kopi arabika menggunakan metode hayami (tabel 1). Adanya perlakuan pada kopi memberikan pertambahan nilai pada kopi tersebut maka digunakan analisis nilai tambah metode hayami sehingga akan diketahui selisih harga antara biji kopi dan bubuk kopi arabika fullwash dan natural yang diperoleh pelaku agroindustri kopi Kelompok Tani Sejahtera.

Agroindustri kopi arabika di kelompok tani sejahtera memperoleh pengembangan nilai tambah atau tidak dapat dilihat dari kategori apabila nilai tambah lebih dari nol maka dikatakan agroindustri kopi arabika kelompok tani sejahtera memperoleh nilai tambah hasilnya positif. Nanum jika kurang dari nol maka dikatakan tidak memberikan nilai tambah hasilnya negative.

Tabel 1. Perhitungan nilai tambah

\begin{tabular}{|c|c|}
\hline Variabel & Nilai \\
\hline \multicolumn{2}{|l|}{ Output, Input dan Harga } \\
\hline 1. Output (Kg/Siklus) & A \\
\hline 2. Bahan baku (Kg/ Siklus) & B \\
\hline 3. Tenaga kerja (JKO) & C \\
\hline 4. Faktor konversi (1:2) & $D=A / B$ \\
\hline 5. Koefisien tenaga kerja $(3: 2)$ & $E=C / B$ \\
\hline Harga output $(\mathrm{Rp} / \mathrm{Kg})$ & $\mathrm{F}$ \\
\hline 7. Upah rata-rata tenaga kerja (Rp/JKO) & G \\
\hline \multicolumn{2}{|l|}{ Pendapatan dan Keuntungan (Rp/Kg bahan baku) } \\
\hline 8. Harga bahan baku(Rp/Kg) & $\mathrm{H}$ \\
\hline Harga input lain $(\mathrm{Rp} / \mathrm{Kg})$ & 1 \\
\hline 10. Nilai output $(4 \times 6)$ & $J=D \times F$ \\
\hline 11. a. Nilai tambah (10-8-9) & $\mathrm{K}=\mathrm{J}-\mathrm{H}-\mathrm{I}$ \\
\hline b. Rasio nilai tambah [(11a:10)×100\%] & $L \%=K / J \times 100 \%$ \\
\hline 12. a. Imbalan tenaga kerja $(5 \times 7)$ & $M=E \times G$ \\
\hline b. Bagian tenaga kerja [(12a:11a)×100\%] & $\mathrm{N} \%=\mathrm{M} / \mathrm{K} \times 100 \%$ \\
\hline 13. a. Keuntungan $(11 a-12 a)$ & $\mathrm{O}=\mathrm{K}-\mathrm{M}$ \\
\hline b. Tingkat keuntungan [(13a:10) $\times 100 \%]$ & $\mathrm{P} \%=\mathrm{O} / \mathrm{J} \times 100 \%$ \\
\hline \multicolumn{2}{|l|}{ Balas Jasa Pemilik Faktor Produksi } \\
\hline 14. Marjin (10-8) & $\mathrm{Q}=\mathrm{J}-\mathrm{H}$ \\
\hline a. Pendapatan tenaga kerja & $R \%=M / Q \times 100 \%$ \\
\hline b. Sumbangan input lain & $S \%=I / Q \times 100 \%$ \\
\hline c. Keuntungan perusahaan & $\mathrm{T} \%=\mathrm{O} / \mathrm{Q} \times 100 \%$ \\
\hline
\end{tabular}

\section{HASIL DAN PEMBAHASAN}

\section{Karakteristik Responden}

Kelompok Tani Sejahtera didirikan pada tahun 2010. Kelompok Tani ini merupakan usaha skala kecil yang didirikan dan diketuai oleh bapak Siswono sebagai penggagas di dirikannya kelompok ini, dimana terdiri dari 19 anggota. Setiap anggota yang terdaftar di kelompok tani ini semuanya memiliki kebun kopi dengan luas 0,5 hingga $7 \mathrm{Ha}$. Kopi yang di proses diolah di suatu tempat yang kemudian di pasarkan dengan label kelompok. Kopi yang pernah menjuarai kontes kopi 
di tingkat nasional pada tahun 2010 memiliki daya tarik didalamnya, peran promosi dan pemasaran yang ada di kelompok tani ini dapat membuat produk kopi mampu dikenal oleh masyarakat luas. Secara umum karakteristik responden anggota kelompok tani sejatera meliputi umur, tingkat pendidikan luas lahan seperti pada Tabel 2.

Tabel 2. Karakteristik anggota Kelompok Tani Sejahtera

\begin{tabular}{ccrc}
\hline No & \multicolumn{1}{c}{ Karakteristik Responden } & Jumlah & Persentasi (\%) \\
\hline 1 & Usia (tahun) & & \\
& $15-64$ & 19 & 100 \\
& $>64$ & 0 & 0 \\
\hline 2 & Tingkat Pendidikan & 3 & 15,79 \\
& SD & 3 & 31,58 \\
& SMP & 9 & 47,37 \\
& SMA & 1 & 5,26 \\
& Perguruan Tinggi & & 0 \\
& Luas Lahan (ha) & 0 & 73,69 \\
& $<0,5$ & 14 & 26,31 \\
\hline
\end{tabular}

Sumber : Diolah dari data primer (2020)

Petani kopi arabika di wilayah penelitian tergolog usia produktif karena 100\% masih berusia antara 15-64 tahun. Menurut (Nursan, Nabilah, Made, \& Sari, 2020) usia produktif akan dapat menerima adopsi dan teknologi dengan baik. Tingkat pendidikan sebanyak $47,37 \%$ adalah lulusan SMA. Hal ini mengindikasikan tingkat pendidikan anggota kelompok tani sejahtera rata-rata ada pada kategori tinggi. Semakin tinggi tingkat pendidikan akan mempengaruhi kemmapuan petani berpikir untuk memahami arti pentingnya usahatani kopi yang baik. Sementara itu luas lahan yang dimiliki oleh responden tergolong pada luas lahan perkebunan kopi sedang sebanyak $73,69 \%$ memiliki luas lahan antara 0,5-2 ha dan sebanyak 26,31 mempunyai luas lahan lebih dari 2 ha dengan kategori luas. Menurut (Hulu et al., 2017) luas lahan petani menjadi salah satu faktor penting dalam mengelola usahatani perkebunan karena menentukan jumlah produk yang dihasilkan.

\section{Analisa Nilai Tambah Kopi Arabika Fullwash dan Natural}

Nilai tambah agroindustri kopi arabika fullwash dan natural yang dihitung merupakan hasil produksi selama satu kali produksi (1 minggu). Pengolahan sebanyak $1 \mathrm{~kg}$ kopi arabika biji menjadi kopi arabika bubuk jenis fullwash rata-rata mendapatkan pertambahan nilai sebesar Rp.50.600 dengan rasio sebesar $40,48 \%$ yang berarti petani kopi akan mendapatkan nilai tambah sebesar Rp. 40,48,- pada setiap Rp. 100,- nilai produk. Nilai tambah ini sama dengan pengolahan untuk $48 \mathrm{~kg}$ kopi arabika biji menjadi kopi arabika bubuk jenis natural. Nilai tambah kopi arabika menjadi bubuk fullwash dan natural ini lebih tinggi jika dibandingkan dengan nilai tambah kopi arabika menjadi Kopi HS dan kopi bubuk yang berdasarkan penelitian (Dewi et al., 2015) diperoleh nilai tambah sebesar Rp. $1.875,05 / \mathrm{kg}$, pada kopi bubuk 100 gram dan 200 gram Rp. Sama-sama memperoleh nilai tambah $6.642,34 / \mathrm{kg}$. Begitu juga dengan hasil penelitian (Sembiring, Satriawan, \& Tuningrat, 2015) yang menyebutkan pengolahan kopi arabika secara basah hanya memberikan nilai tambah $R p .770,22 / \mathrm{kg}$ dan secara kering Rp. 18,59/kg. Berdasarkan kriteria menurut hayami nilai tambah $>0$ yang berarti pengembangan agroindustri kopi arabika fullwash dan natural memberikan nilai tambah yang positif. Sementara menurut (Ramawati, Soedarto, \& Nurhadi, 2019), rasio nilai tambah dikatakan tinggi apabila memiliki persentase diatas $>40 \%$. Sehingga rasio nilai tambah agroindustri kopi arabika fullwash dan natural di kelompok tani sejahtera berada pada kategori rasio nilai tambah tinggi karena memiliki persentase lebih dari $40 \%$.

Hasil penelitian ini sejalan dengan Tamaradewi, Miftah, \& Yoesdiarti (2019) bahwa rasio nilai tambah kopi arabika dengan full wash process dan natural proscess yang positif pada kelompok tani hutan Cibulao Hijau dengan nilai tambah kopi bubuk yang lebih $>0$, namun berada pada golongan rasio nilai tambah sedang karena ada pada persentase antara 15\% - 40\%. Yoga Priantara, Mulyani, \& Satriawan (2017) juga menyebutkan bahwa nilai tambah kopi arabika kintamani bangli menjadi kopi bubuk ada pada kategori nilai tambah yang tinggi karena mencapai $92 \%$. Berbeda halnya dengan pengolahan primer kopi arabika Kabupaten Simalungun yang berada pada rasio nilai tambah sedang karena rasio sebesar 30\%.(Saragih, 2019). Namun nilai tambah ini masih belum dikurangi dengan biaya tenaga kerja sehingga nilai tersebut masih nilai tambah kotor dari pengurangan nilai produk dengan harga bahan baku dan sumbangan input lain. 
Tabel 3. Analisis nilai tambah agroindustri kopi arabika fullwash dan natural di Kelompok Tani Sejahtera Desa Kayumas Kecamatan Arjasa

\begin{tabular}{lrr}
\hline \multicolumn{1}{c}{ Variabel } & Fullwash & Natural \\
\hline Output, Input dan harga & & \\
1. Hasil Produksi (kg) & 50 & 40 \\
2. Bahan Baku (kg) & 60 & 48 \\
3. Tenaga Kerja (JKO) & 24 & 24 \\
4. Faktor Konversi & 0,83 & 0,83 \\
5. Koefisien Tenaga Kerja (JKO/kg) & 0,4 & 0,5 \\
6. Harga Produk (Rp/kg) & 150,000 & 150,000 \\
7. Upah rata-rata tenaga kerja (Rp/JKO) & 7,500 & 7,500 \\
\hline Pendapatan dan Keuntungan & & \\
\hline 8. Harga bahan baku (Rp/kg) & 60,000 & 60,000 \\
9. Sumbangan input lain(Rp/kg) & 14,400 & 14,400 \\
10. Nilai produk (Rp/kg) & 125,000 & 125,000 \\
11. a. Nilai Tambah (Rp/kg) & 50,600 & 50,600 \\
b. Rasio Nilai Tambah (\%) & 40,48 & 40,48 \\
12.a. Imbalan Tenaga Kerja (Rp/kg) & 3,000 & 3,750 \\
b. Pangsa Tenaga Kerja (\%) & 5,6 & 7,41 \\
13. a. Keuntungan (Rp/kg) & 47,600 & 46,850 \\
b. Tingkat Keuntungan (\%) & 94,07 & 92,6 \\
\hline
\end{tabular}

Sumber : Diolah dari data primer (2020)

Total jam kerja untuk memproduksi kopi arabika baik untuk jenis fullwash maupun natural adalah 1 kali produksi,Total jam kerja diperoleh dari hasil perkalian jumlah jam kerja orang per hari dengan banyaknya tenaga kerja sehingga diketahui jumlah total jam kerja adalah $24 \mathrm{JKO}$. Sementara itu tenaga kerja (JKO) dibagi dengan jumlah bahan baku yang dipakai oleh petani dalam 1 kali produksi akan menjadi nilai koefisien tenaga kerja. Pada produksi kopi arabika fullwash diketahui nilai koefisiennya adalah $0,4 \mathrm{JKO} / \mathrm{kg}$ dan $0,5 \mathrm{JKO} / \mathrm{kg}$ untuk kopi arabika natural. Biaya tenaga kerja per JOK sebesar Rp. 7.500.

Sumbangan input lain untuk kopi arabila fullwash maupun natural sebesar Rp 14.400/kg. Nilai tersebut diperoleh dari penjumlahan antara biaya bahan tambahan setiap $\mathrm{kg}$ dengan biaya penyusutan dalam 1 kali produksi. Faktor konversi dikali dengan harga produk maka akan menghasilkan nilai produk kopi arabika yaitu Rp 125.000,- per kg. Hasil perhitungan nilai tambah kopi arabika fullwash dan natural dapat dilihat pada tabel 3.

Nilai koefisien tenaga kerja jika dikalikan dengan rata-rata upah tenaga kerja maka akan dihasilkan imbalan tenaga kerja yaitu sebesar Rp. 7.500,-. Pendapatan tenaga kerja langsung didapat dari koefisien tenaga kerja langsung dikalikan dengan upah tenaga kerja langsung yaitu sebesar $\mathrm{Rp}$ $3.000 \mathrm{Kg}$ untuk produksi kopi bubuk arabika fullwash dengan prosentase imbalan tenaga kerja terhadap nilai tambah sebesar $5,6 \%$ sementara untuk kopi bubuk arabika natural diperoleh nilai imbalan tenaga kerja Rp.3.750 dan 7,41\% untuk prosentase imbalannya.

Nilai tambah dikurangi imbalan tenaga kerja maka akan diketahui keuntungan yang diperoleh oleh kelompok tani. Kelompok tani sejahtera mendapatkan keuntungan sebesar Rp 47.600,- atau apabila dipersentase didapat keuntungan $94,07 \%$ dari nilai produk kopi arabika fullwash. Keuntungan untuk kopi arabika natural lebih rendah yaitu Rp. 46.850 atau tingkat keuntungan 92,6\%. Keuntungan tersebut merupakan total keuntungan setiap produksi kopi arabika. Keuntungan pengolahan kopi arabika menjadi kopi arabika bubuk jenis fullwash dan natural di Desa Kayumas Kecamatan Arjasa ini lebih tinggi jika dibandingkan dengan pengolahan kopi arabika yang dikelola oleh Unit Pengolahan Hasil di Desa Belok Sidan (Atmaja, Tamba, \& Kardi, 2015). Petani kopi di Desa Belok Sidan Kecamatan Petang Kabupaten Badung ini memperoleh keuntungan pengolahan kopi OC arabika Rp. $1.283,33 / \mathrm{kg}$ kopi dan kopi bubuk sebesar Rp. 22.260/kg. Penelitian Epaga et al., (2019) juga menunjukan bahwa agroindustri KSU Sara Ate dalam mengolah kopi arabika menjadi green bean grade 1 menyumbangkan keuntungan sebesar Rp. 19.900/kg juga masih berada dibawah angka keuntungan yang diperoleh oleh Kelompok Tani Sejahtera Desa Kayumas Kecamatan Arjasa.

Tingginya keuntungan yang diperoleh petani anggota Kelompok Tani Sejatera Desa Kayumas ini dipengaruhi oleh tingginya harga produk kopi arabika jenis fullwash dan natural yang mencapai Rp. $150.000 / \mathrm{kg}$. Selain itu biaya tenaga kerja juga tergolong murah sehingga mempengaruhi tingginya nilai tambah dan keuntungan yang diperoleh petani. 


\section{KESIMPULAN}

Pengembangan agroindustri kopi bubuk arabika fullwash dan natural memiliki prospek yang sangat baik bagi Kelompok Tani Sejahtera karena tingginya nilai tambah yang diperoleh dari usaha ini yang mencapai $40,48 \%$. Selain itu temuan dari penelitian ini adalah sangat tingginya tingkat keuntungan petani dari hasil pengolahan kopi arabika menjadi kopi arabika bubuk jenis fullwash hingga $94,07 \%$ dan natural mencapai 92,6\% dibandingkan dengan agroindustri kopi arabika lainnya.

\section{REFERENSI}

Atmaja, I., Tamba, I., \& Kardi, C. (2015). Peningkatan Pendapatan Petani Kopi Arabika Peserta Unit Pengolahan Hasil (UPH)(Kasus Di Desa Belok Sidan Kecamatan Petang Kabupaten. Jurnal Agrimeta, 5(10), 32-42. Retrieved from http://jurnal.unmas.ac.id/index.php/agrimeta/article/view/134

BPS Kabupaten Situbondo. (2020). Kabupaten Situbondo dalam Angka 2020 (BPS Kabupaten Situbondo, ed.). BPS Kabupaten Situbondo.

Dewi, N., Budiasa, I., \& Dewi, I. (2015). Analisis Finansial Dan Nilai Tambah Pengolahan Kopi Arabika Di Koperasi Tani Manik Sedana Kabupaten Bangli. E-Journal Agribisnis Dan Agrowisata (Journal of Agribusiness and Agritourism), 4(2), 98.

Epaga, P., Baihaqi, A., Susanti, E., Agribisnis, P. S., Pertanian, F., Kuala, U. S., Ekspor, K. A. (2019). Analisis nilai tambah agroindustri pengolahan kopi arabika ekspor di kabupaten aceh tengah (studi kasus pada ksu sara ate) 1. Jurnal Agribisnis Dan Sosial Ekonomi Pertanian UNPAD, 4(2528), 602-611.

Fauziah, U., \& Ihwana, A. (2015). Analisis Rantai Nilai Distribusi Kopi di Kabupaten Garut. Jurnal Kalibrasi, 1(13), 1-8.

Hariyati, Y. (2014). Pengembangan Produk Olahan Kopi Di Desa Sidomulyo Kecamatan Silo Kabupaten Jember. Agriekonomika, 3(1), 81-91.

Harlina Dewi, K., Nusril, N., Helmiyetti, H., Rosalina, Y., \& Sarumpaet, P. (2013). Analisis Nilai Tambah Kopi Teripang Jahe Pra Campur Saset. Jurnal AGRISEP, 12(2), 209-216. https://doi.org/10.31186/jagrisep.12.2.209-216

Hayami, Y. (1987). Agricultural marketing and processing in upland Java. Retrieved from https://agris.fao.org/agris-search/search.do?recordID=US201300611364

Hulu, H. La, Marsuki Iswandi, R., Indarsyih, Y., Jurusan, A., Fakultas, A., Uho, P., \& Jurusan, P. (2017). Faktor-Faktor Yang Mempengaruhi Konversi Lahan Perkebunan Cengkeh Di Desa Tolong Kecamatan Lede Kabupaten Pulau Taliabu Provinsi Maluku Utara. Jurnal IImiah Agribisnis (Jurnal Agribisnis Dan IImu Sosial Ekonomi Pertanian), 2(1), 24-28. https://doi.org/10.33772/jia.v2i1.6692

Murbaningtyas, V., Sukiyono, K., \& Badrudin, R. (2020). Nilai Tambah dan Kelayakan Usaha Pengolahan Kopi Pada Kelompok Perkasa Tani di Desa IV Suku Menanti Kecamatan Sindang Dataran Kabupaten Rejang Lebong. Jurnal Ekonomi Pertanian Dan Agribisnis (JEPA), 4(4), 872.

Nursan, M., Nabilah, S., Made, N., \& Sari, W. (2020). Kertasari Kabupaten Sumbawa Barat. 2748(2012).

Ramawati, R., Soedarto, T., \& Nurhadi, E. (2019). Pengolahan Kopi Dan Analisis Nilai Tambah Kopi Robusta Di Kecamatan Tutur Kabupaten Pasuruan. Berkala IImiah Agribisnis AGRIDEVINA, 8(2), 135-144. https://doi.org/10.1017/CBO9781107415324.004

Ramawati, R., Soedarto, T., Nurhadi, E., Kopi, P., Analisis, D., Nilai, D. A., ... Anyar, S. (2019). Coffee Treatment And Analysis Value Added Robusta Coffee In Tutur Pasuruan District. Berkala IImiah Agribisnis AGRIDEVINA, 8(2), 135-144.

Saragih, J. R. (2019). Pendapatan dan Nilai Tambah Pengolahan Primer Kopi Arabika di Desa Sait Buttu Saribu, Kecamatan Pamatang Sidamanik, Kabupaten Simalungun. Journal of Regional and Rural Development Planning, 3(1), 1. https://doi.org/10.29244/jp2wd.2019.3.1.1-10

Sembiring, N., Satriawan, I., \& Tuningrat, I. (2015). Nilai Tambah Proses Pengolahan Kopi Arabika Secara Basah (West Indischee Bereding) Dan Kering (Ost Indischee Bereding) Di Kecamatan Kintamani, Bangli. Jurnal Rekayasa Dan Manajemen Agroindustri, 3(1), 61-72. Retrieved from https://ojs.unud.ac.id/index.php/jtip/article/view/16899

Subaeni, E., Badrudin, R., \& Reswita, R. (2017). Analisis Nilai Tambah Dan Cost Volume Profit Usaha Pengolahan Kopi Sahabat Di Kota Lubuk Linggau Sumatera Selatan. Jurnal Agribisnis Terpadu, 10(2), 175. https://doi.org/10.33512/jat.v10i2.5069

Tamaradewi, R., Miftah, H., \& Yoesdiarti, A. (2019). Analisis Nilai Tambah Dan Strategi 
Pengembangan Usaha Kopi (Coffea sp) Di Kelompok Tani Hutan (Kth) Cibulao Hijau. Jurnal AgribiSains, 5(2).

Yoga Priantara, I., Mulyani, S., \& Satriawan, I. (2017a). Analisis Nilai Tambah Pengolahan Kopi Arabika Kintamani Bangli. Jurnal Rekayasa Dan Manajemen Agroindustri, 4(4), 34.

Yoga Priantara, I., Mulyani, S., \& Satriawan, I. (2017b). Analisis Nilai Tambah Pengolahan Kopi Arabika Kintamani Bangli. Jurnal Rekayasa Dan Manajemen Agroindustri, 4(4), 33 - 42. 